\title{
Viewpoint
}

\section{Recent Graduates Experience Difficulty in Finding Positions Despite Apparent Need for More Pediatric Cardiologists in Canada}

\author{
Antoine Déry, ${ }^{a}$ Marylyn Lévesque, BSc, ${ }^{a}$ Claudia Renaud, MD, ${ }^{b}$ Kevin Harris, MD, MHSc, ${ }^{c}$ and \\ Frédéric Dallaire, $\mathrm{MD}, \mathrm{PhD}^{\mathrm{a}}$ \\ ${ }^{a}$ Department of Pediatrics, Université de Sherbrooke and Centre de Recherche du Centre Hospitalier Universitaire de Sherbrooke, Sherbrooke, Quebec, Canada \\ ${ }^{b}$ Department of Pediatrics, McGill University Health Centre, Montreal, Quebec, Canada \\ ${ }^{c}$ Children's Heart Centre, British Columbia Children's Hospital, Vancouver, British Columbia, Canada
}

\begin{abstract}
There have been reports that pediatric cardiology is an increasingly competitive field and that it has become difficult for recent graduates to find employment. In Canada, empirical observations are consistent with these findings, but this has not been formally evaluated. The aim of this study was to survey pediatric cardiologists (PCs) on their perception of the current workforce in Canada. A survey was sent to PCs and trainee members of the Canadian Pediatric Cardiology Association in November 2017. Eligible nonmembers of the Canadian Pediatric Cardiology Association were also contacted with the help of Canadian program directors and division chiefs. A total of 68 of 83 PCs completed the survey (82\%). The proportion of respondents reporting difficulties in finding a stable position in pediatric cardiology was $83 \%$ for those finishing training after 2014 compared with 33\% between 2010 and 2014. There was a concomitant increase in the duration of additional subspecialization, which more than doubled after 2014. This contrasted with most PCs (57\%) and division chiefs (86\%) reporting being understaffed, and with a higher number of anticipated
\end{abstract}

In the last 2 decades, the number of pediatric cardiologists (PCs) in North America has increased. A recent study in the United States showed that pediatric cardiology was increasingly competitive and that there was an oversupply of trainees with respect to anticipated openings. ${ }^{1}$

Received for publication December 17, 2018. Accepted January 22, 2019.

Ethics Statement: Ethics approval was obtained from the Research Ethics Board of the Centre de Recherche du CHUS and the CIUSSS de l'Estrie CHUS, $300112^{\mathrm{e}}$ Avenue Nord, Office 2929, Sherbrooke, Québec, Canada, J1N 5 N4.

Corresponding author: Dr Frédéric Dallaire, Centre de Recherche du Centre Hospitalier Universitaire de Sherbrooke, 3001, $12^{\mathrm{e}}$ Avenue Nord, Sherbrooke, Québec J1N 5N4, Canada. Tel.: +1-819-346-1110 ×70454.

E-mail: frederic.a.dallaire@usherbrooke.ca

See page 52 for disclosure information.

\section{RÉSUMÉ}

Des études ont montré que la cardiologie pédiatrique est un domaine de plus en plus concurrentiel. Conséquemment, les diplômés actuels ont du mal à trouver de l'emploi. Au Canada, des observations empiriques sont cohérentes avec ces conclusions, mais aucune évaluation formelle n'a été réalisée. L'objectif de la présente étude était de mener une enquête auprès des cardiologues pédiatres (CP) sur leur perception de la main-d'œuvre actuelle au Canada. En novembre 2017, nous avons envoyé un sondage aux CP et aux résidents membres de l'Association canadienne de cardiologie pédiatrique. Nous sommes également entrés en contact avec les nonmembres admissibles de l'Association canadienne de cardiologie pédiatrique par l'intermédiaire des directeurs de programmes et des chefs de division. Soixante-huit des quatre-vingt-trois CP ont rempli l'enquête $(82 \%)$. Le pourcentage des répondants qui ont rapporté avoir des difficultés à trouver un poste stable en cardiologie pédiatrique était de $83 \%$ chez ceux ayant terminé leur formation après 2014 , alors que le pourcentage était de $33 \%$ chez ceux ayant

In Canada, anecdotal reports suggest increasing difficulty in finding employment resulting in longer additional subspecialization. However, data substantiating this are scarce. In 2012, an oversupply of pediatric cardiology trainees in Canada was reported. ${ }^{2}$ In the last decade, the number of trainees who took the Canadian certification examination in Pediatric Cardiology has declined (personal communication from the Royal College of Physicians and Surgeons of Canada [RCPSC], 2017). Data from the RCPSC also show that between 2011 and 2015, quotas in pediatric cardiology residency positions were not met despite being lower than in the previous years. $^{3}$

Data on the current workforce and projected needs in Canada would be helpful to determine the optimal number of trainees, to inform trainees regarding potential career choices, and to assist with long-term planning of staff positions. The 
openings compared with available trainees. Division chiefs reporting being understaffed mostly attributed this to government regulations or institutional budgetary constraints. We observed a discrepancy between a perceived need for additional PCs and a reported increasing difficulty in finding employment by recent graduates. This coincided with an increasing number of additional subspecialization years by recent graduates. Institutional and government restrictions may contribute to this situation.

purpose of this study was to survey PCs and trainees on their perception of the current workforce in Canada.

\section{Methods}

\section{Study design and population}

This is a cross-sectional study targeting Canadian PCs, trainees intending to practice in Canada, fellowship program directors, and division chiefs. We were mandated by The Canadian Pediatric Cardiology Association (CPCA) to survey the actual pediatric cardiology workforce. The CPCA is an affiliate member of the Canadian Cardiovascular Society and includes most of the practicing PCs in Canada (83 members at the time of the survey). The CPCA sent out the survey to its members, and we directly contacted the program directors of the 8 Canadian pediatric cardiology training programs and the 15 division chiefs to identify practicing PCs who may not be active members of the CPCA. The survey was conducted between November 2017 and March 2018, and participants were encouraged to share the survey with potentially eligible colleagues and trainees who may not be members of the CPCA. Topics included training history, perception of the working environment, ease of finding employment, waiting list, perceived adequacy of the number of practicing PCs in relation to their community's needs, and recent or anticipated openings. Eligibility criteria are listed in Table 1. Identifying data were automatically stripped from the dataset, and only anonymized data were available for analysis. The first question of the survey contained an agreement to participate after providing informed consent. The research ethics board of the Centre de Recherche du CHUS reviewed and approved this study.

\section{Questionnaire}

The survey was adapted from questions used in previous workforce surveys in pediatrics, cardiology, pediatric cardiology, or postgraduate fellowship training. We adapted questions from the 2015 workforce survey in pediatric cardiology in the United States, ${ }^{1}$ the National Academic Paediatric Workforce Database, ${ }^{2}$ and the 2015 final-year medical residents survey in the United States. ${ }^{4}$ The complete survey is available as Supplementary Material. We used the survey tool terminé leur formation entre 2010 et 2014 . La durée des formations en surspécialité a augmenté de manière concomitante et a plus que doublé après 2014. Ces données entraient en contradiction avec les commentaires de la plupart des CP (57\%) et des chefs de division (86 \%) qui, disaient manquer de personnel et avoir un nombre anticipé plus de postes vacants plus élevés que le nombre de résidents disponibles. Les chefs de division qui rapportaient manquer de personnel attribuaient principalement cela à des contraintes gouvernementales ou budgétaires. Nous avons observé des contradictions entre les besoins perçus pour des $\mathrm{CP}$ additionnels et la difficulté croissante que rapportent les diplômés actuels à trouver de l'emploi. Ceci coïncide avec un nombre croissant d'années supplémentaires de formation en surspécialisation. Des contraintes institutionnelles ou gouvernementales contribuent possiblement à cette situation.

of the online data-collection software REDCap (Vanderbilt University, Nashville, TN). ${ }^{5}$

\section{Statistical analysis}

Data are presented using descriptive statistics. For duration of additional subspecialization, we present mean and standard deviation. Duration of additional subspecialization was not normally distributed, but mean and standard deviation were more informative than median and interquartile range. Groups were compared using the nonparametric Wilcoxon 2sample test for continuous variables and Fisher exact test proportions. We used SAS for Windows version 9.4 for all analyses (SAS Institute Inc, Cary, NC).

\section{Results}

Seventy-nine questionnaires were completed, and 3 were excluded because they did not fulfill eligibility criteria. Sixtyeight questionnaires were filled by PCs and 8 by trainees. The survey was sent to the 83 PCs who were active members of the CPCA (response rate of $82 \%$ ). We encouraged respondents to share the survey link with PCs who are nonmembers of the CPCA. Considering that 100 PCs were licensed to practice in 2015 (RCPSC data), 68\% of practicing PCs responded to the survey. The return rate from program directors and division chiefs was 75\% (6/8) and 93\% (14/15), respectively. It was not possible to calculate a response rate for trainees because those currently training abroad were eligible but their number was not known.

\section{Demographics and profiles of practice for PCs}

Table 2 details the reported demographics of all 79 respondents. The majority of participants were male (60\%), and the most represented age group was 45 to 54 years $(41 \%)$. The majority $(87 \%)$ reported being employed in a hospital affiliated with an academic institution. Most respondents completed their core pediatric cardiology training at a Canadian institution (81\%).

\section{Training for PCs}

Most PCs (65\%) had completed additional subspecialization after the 3 years of core fellowship, with 68\%, 23\%, and $9 \%$ completing 1 year, 2 years, and 3 or more years, respectively. Subspecialization was done most often in imaging 
Table 1. Eligibility criteria for pediatric cardiologist and trainees

\begin{tabular}{|c|c|}
\hline Professional situation & Criteria/definition \\
\hline Pediatric cardiologists & $\begin{array}{l}\text { - A medical professional with board certification in pediatric cardiology who is currently practicing mainly in the field } \\
\text { of fetal or pediatric cardiology in Canada }\end{array}$ \\
\hline $\begin{array}{l}\text { Pediatric cardiology trainee } \\
\text { currently training in Canada }\end{array}$ & $\begin{array}{l}\text { - A candidate training in a Canadian university in a pediatric cardiology core fellowship program (postgraduate year } \\
4,5 \text {, or } 6 \text { ) who intends to practice pediatric cardiology in Canada after training; OR } \\
\text { - A candidate currently enrolled in a pediatric cardiology subspecialty fellowship in a Canadian pediatric cardiology } \\
\text { fellowship program who intends to practice pediatric cardiology in Canada after training; OR } \\
\text { - A candidate done with cardiology training aiming to work in Canada who has not yet found a permanent position } \\
\text { in pediatric cardiology }\end{array}$ \\
\hline $\begin{array}{l}\text { Pediatric cardiology trainee } \\
\text { currently training outside Canada }\end{array}$ & $\begin{array}{l}\text { - A candidate with an MD or a specialty training done in a Canadian university; AND } \\
\text { - A candidate currently training in a pediatric cardiology core fellowship program or a pediatric cardiology } \\
\text { subspecialty program; AND } \\
\text { - A candidate intending to come back to Canada to practice pediatric cardiology }\end{array}$ \\
\hline
\end{tabular}

(29\%), electrophysiology (15\%), and catheterization (15\%). Half of respondents completed their first year of additional subspecialization outside of Canada.

In the last 4 years, there has been a 2 -fold increase in the number of years of additional subspecialization (Fig. 1). The mean number of years of additional subspecialization was $0.8 \pm 0.8$ year until 2013 compared with $1.9 \pm 1.0$ years from 2014 onward $(P<0.01)$. As shown in Figure 2 , the proportion of respondents who undertook additional subspecialization based on personal choice decreased from $72 \%$ for the first year of additional subspecialization to $55 \%$ for the second year and to $33 \%$ for the third year $(P<0.05)$.

\section{Recently filled positions and potential openings}

Twenty-four new hires were reported by division chiefs over the last 2 years. Of these, $18(75 \%)$ positions were filled by recently graduated trainees. All of them have done additional subspecialization. Division chiefs anticipated they would have a total of 21 open positions in the next 2 years. Sixty-four percent of division chiefs mentioned that 1 year of additional subspecialization was usually sufficient to obtain a position in their division.

\section{Understaffing}

When asked about the number of colleagues practicing in their area, $51 \%$ of PCs reported that it was insufficient, $45 \%$ reported that it was adequate, and $3 \%$ reported that it was excessive. These proportions were evenly distributed between PCs affiliated with an academic institution and PCs who were not. Figure 3 shows that PCs reporting an insufficient number of colleagues also reported longer wait lists for elective

Table 2. Demographic characteristics

\begin{tabular}{lc}
\hline \hline Characteristics & Number (\%) \\
\hline Respondents & $79(100.0)$ \\
Male gender & $44(56.4)$ \\
Age group & \\
$25-34 \mathrm{y}$ & $11(13.9)$ \\
$35-44 \mathrm{y}$ & $19(24.1)$ \\
$45-54 \mathrm{y}$ & $27(34.2)$ \\
$\geq 55 \mathrm{y}$ & $20(25.3)$ \\
Employment site & \\
Medical school/hospital & $59(86.7)^{*}$ \\
Other & $9(13.3)^{*}$ \\
\hline
\end{tabular}

${ }^{*}$ Excluding trainees. consultations $(P<0.02)$. Most division chiefs $(86 \%)$ also reported being understaffed. Among reasons for being understaffed, division chiefs mentioned government regulations $(60 \%)$, budgetary constraints $(50 \%)$, and difficulty finding appropriate candidates (25\%).

\section{Ease of finding employment}

Despite the majority of PCs and division chiefs reporting being understaffed, and despite most division chiefs reporting open positions, respondents reported increasing difficulty in finding a stable position over time (Fig. 4). For those who finished or will finish training between 2015 and 2020, 83\% described that it was difficult to find employment in their subspecialty. This proportion was $36 \%$ for those who completed training in 2010 to 2014 and $10 \%$ before $2010(P<0.01)$.

\section{Trainees}

All trainees reported having difficulty in finding a position, and $38 \%$ admitted that it was harder than expected. Most trainees $(63 \%)$ reported that finding a stable position was the most stressful issue during their residency. Other reported stressors included work-life balance (13\%), workload (13\%), and exams (13\%). When asked if they would choose pediatric cardiology if they were to begin their education again, 3 of 8 (38\%) responded, "I am not sure."

\section{Discussion}

This is the first survey on the Canadian workforce in pediatric cardiology. The high response rate indicates that this is a topic of interest for our professional community. We report an increase in the perceived difficulty of finding a stable position as a PC in Canada. This corresponded to an increase in the duration of additional subspecialization being pursued, although causality cannot be established by our design. This also contrasted with the reported number of open or anticipated positions and the perceived understaffing by both PCs and division chiefs.

In their recent survey of the U.S. workforce in pediatric cardiology, Ross and colleagues ${ }^{1}$ used a similar methodology and reported a potential oversupply of trainees, which translated into increased difficulty in finding a job. Most American PCs reported increased competition and oversupply of PCs in their area. ${ }^{1}$ Our results contrast with their assessment in that most Canadian PCs and division chiefs reported being understaffed. In Canada, there has been a mean of 6 newly certified 


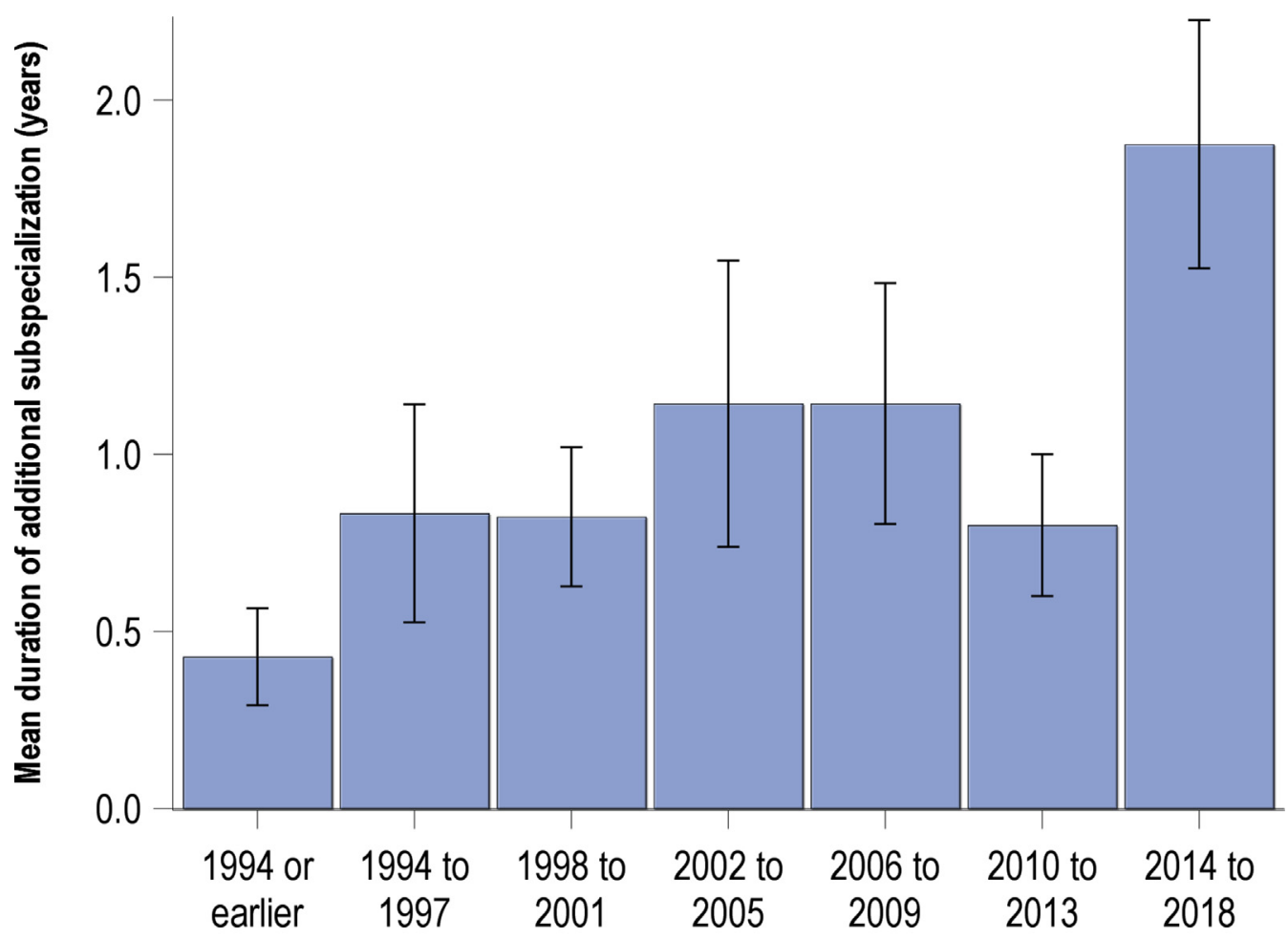

First year of pediatric cardiology practice

Figure 1. Mean number of additional subspecialization years in pediatric cardiology according to first year of practice.

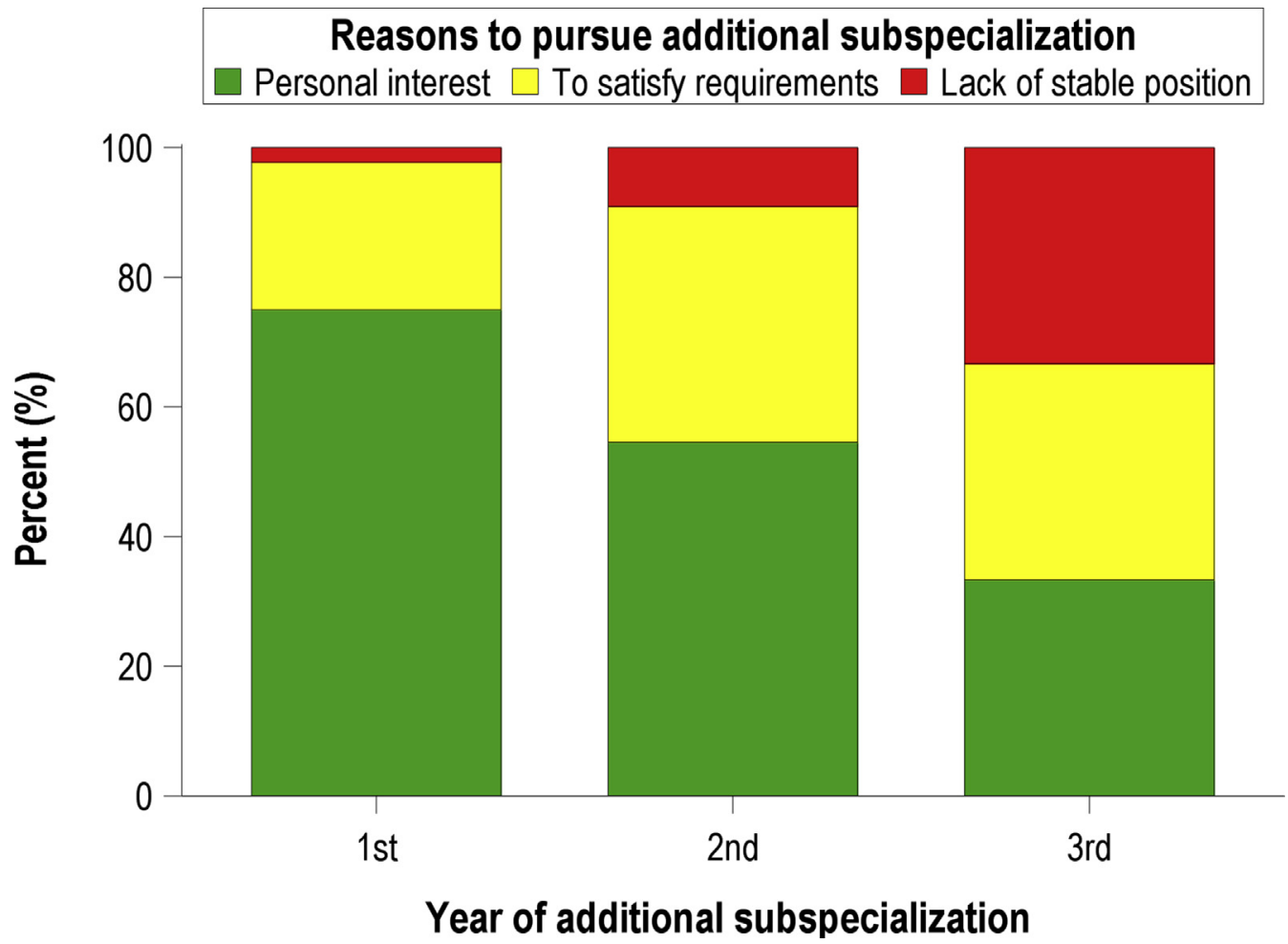

Figure 2. Reported reason to pursue additional subspecialization according to the number of years of training. 


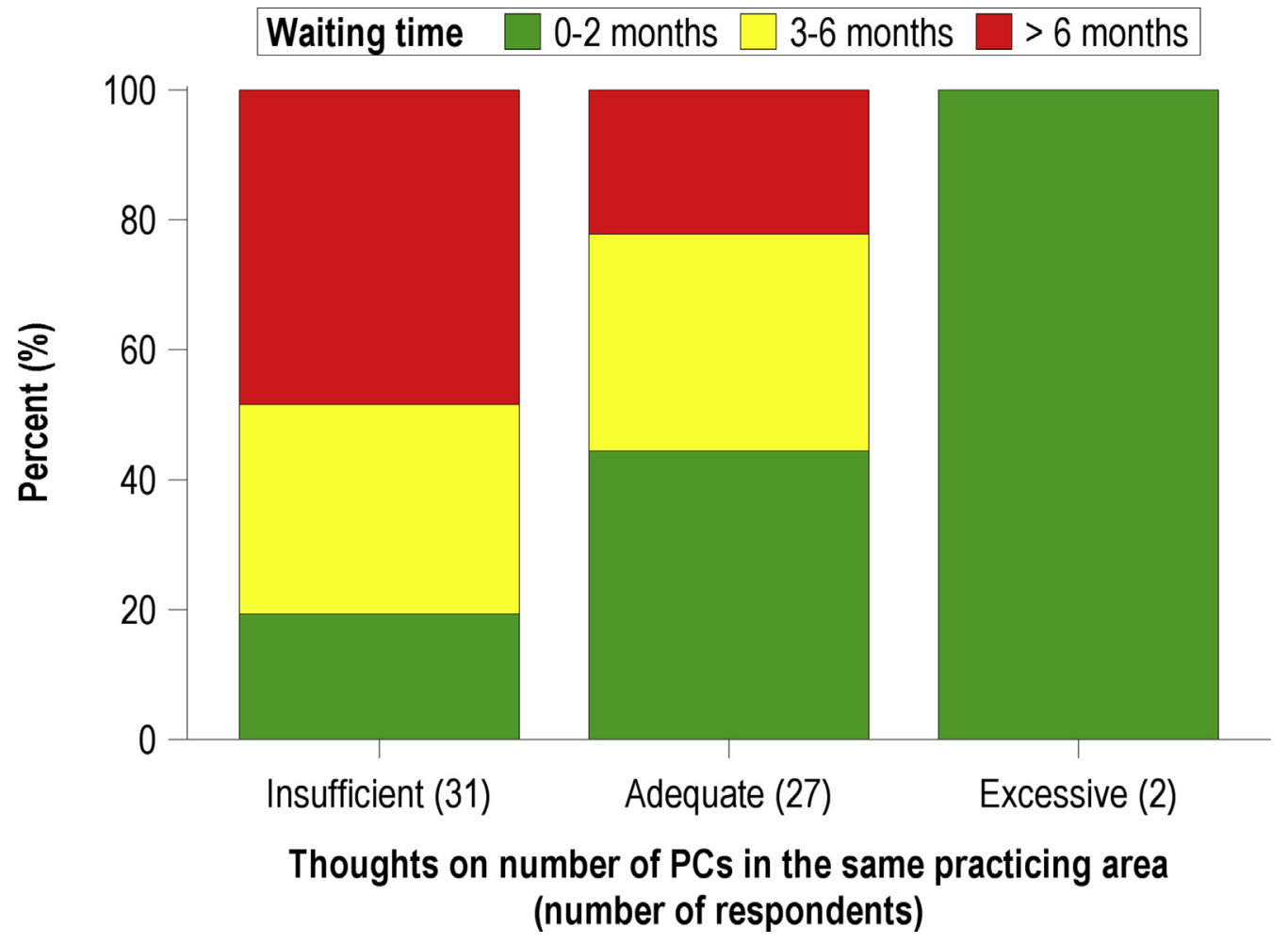

Figure 3. Nonemergency consultation wait time for a new patient according to the perceived adequacy of the number of PCs. PC, pediatric cardiologist.

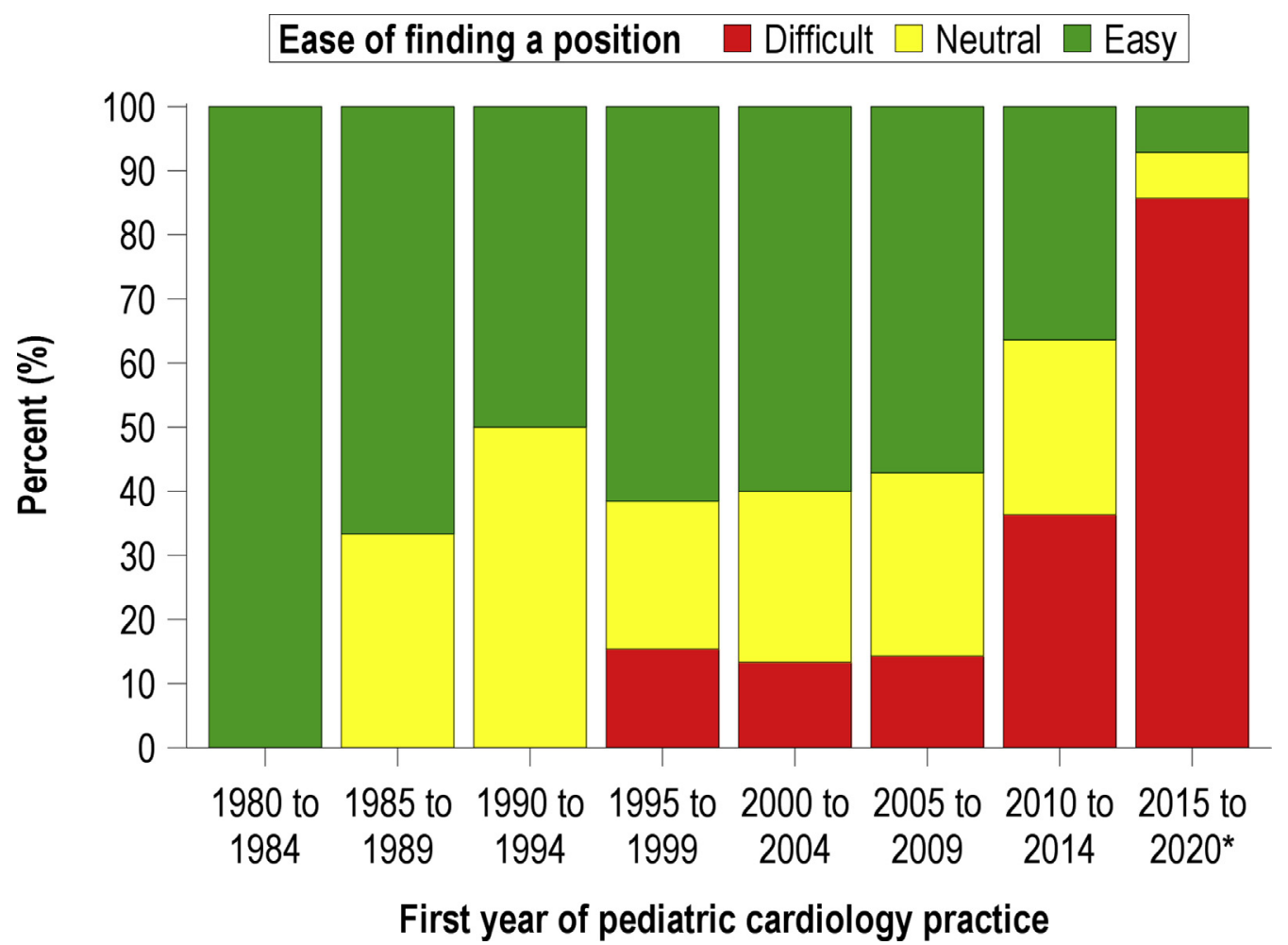

Figure 4. Ease of obtaining a job in pediatric cardiology over the last 40 years. *Includes trainees who expect to have completed training by 2020. 
PCs per year between 2011 and 2015. The number of Canadian residents matching with a Canadian pediatric cardiology training program has been decreasing steadily since 2011 (mean of $<2$ matches/year between 2011 and 2015). ${ }^{3}$ In 2012, it was suggested that the number of trainees in pediatric cardiology in Canada would exceed the anticipated needs. ${ }^{2}$ Our results suggest that there should not be an oversupply of new PCs, unless factors hinder open positions from being filled.

It should be noted that Canada and the United States have different models of practice. The number of PCs per capita is 2.9 per million in Canada compared with 8.9 in the United States. ${ }^{1}$ Moreover, there are more PCs not linked to an academic institution in the United States ${ }^{1}$ in comparison with Canada, where approximately $90 \%$ of PCs reported working in an academic setting. Because the reported potential openings were from division chiefs of academic programs, it is possible that other employment opportunities exist in nonacademic practice models.

The difficulty in finding a position despite the apparent understaffed environment could be explained by external restrictions. When asked about the number of anticipated faculty positions opening over the next 2 years, it is possible that division chiefs included positions that cannot be filled because of budgetary of regulatory restrictions. One could argue that if restrictions exist, division chiefs may advertise more anticipated open positions to advocate for increased resources. In our survey, division chiefs and PCs seemed to agree on being generally understaffed, which was mostly associated with longer wait times. These data suggest that these anticipated positions are mostly not "artificial" and would likely be filled should the restrictions be removed.

It can be inferred that the increasing difficulty of finding a job has driven trainees to engage in longer additional subspecialization. This was substantiated by the parallel trends in the length of additional subspecialization and in the difficulty of finding a position and further supported by the increasing proportion of respondents engaging in longer training because of the lack of an available position. This seems to cause distress in trainees, the first reported source of stress being the lack of a position. In addition, we were disturbed by the $38 \%$ of trainees reporting not being sure they would choose pediatric cardiology if given the opportunity to start over.

\section{Study limitations}

This study has limitations. We recognize that questions and answers in a survey are subjective in nature and that people with strong opinions may be more prone to participate. Our results reflect the respondents' perception and must be interpreted accordingly. Despite the high response rate, the study population is small, and this should be taken into consideration when interpreting the results. The small numbers also precluded the breakdown of results by subgroups, including by province, because it would have jeopardized confidentiality. A recall bias is possible, especially with regard to the ease of finding a job. Finally, the actual number of trainees intending to seek a position in Canada is unknown. Some Canadian trainees may have left Canada to study. International trainees training in Canada may also decide to stay in Canada after their training. The actual adequacy of potential openings vs the number of available trainees to fill them is difficult to determine precisely.

\section{Conclusions}

We report a different workforce environment in Canada compared with the United States. Most PCs reported being understaffed, and unfilled positions exceeded the number of available trainees. However, finding a job as a PC in Canada has become difficult, possibly because of institutional or governmental restrictions. Concurrently, recent and future graduates have engaged in longer subspecialization. We intend to prospectively evaluate the workforce in the future to document changes over time and provide much needed data to support PCs as they engage with hospital leadership and government to advocate for sufficient resources to optimize pediatric cardiovascular care in Canada.

\section{Disclosures}

The authors have no conflicts of interest to disclose.

\section{References}

1. Ross RD, Srivastava S, Cabrera AG, et al. The United States Pediatric Cardiology 2015 Workforce Assessment: a survey of current training and employment patterns: A report of the American College of Cardiology, American Heart Association, American Academy of Pediatrics Section on Cardiology and Cardiac Surgery, and Society for Pediatric Cardiology Training Program Directors. J Am Coll Cardiol 2017;69: $1347-52$.

2. Piedboeuf B, Jones S, Orrbine E, Filler G. Are the career choices of paediatric residents meeting the needs of academic centres in Canada? Paediatr Child Health 2012;17:17-20.

3. Royal College of Physicians and Surgeons of Canada. Royal College Medical Workforce Knowledgebase. Available at: http://www.royalcollege. $\mathrm{ca} /$ rcsite/health-policy/medical-workforce-knowledgebase-e. Accessed March 13, 2019.

4. Miller P. 2015 Survey of of Final-Year Medical Residents. Irving: Merritt Hawkins, 2015.

5. Harris PA, Taylor R, Thielke R, et al. Research electronic data capture (REDCap)-a metadata-driven methodology and workflow process for providing translational research informatics support. J Biomed Inform 2009; $42: 377-81$.

\section{Supplementary Material}

To access the supplementary material accompanying this article, visit CJC Open at https://www.cjcopen.ca/ and at https://doi.org/10.1016/j.cjco.2019.01.004. 